\title{
Charles Tilly's Understanding of Contentious Politics: A Social Interactive Perspective for Social Science
}

\author{
Florence Passy \\ University of Lausanne
}

\begin{abstract}
[Stinchcombe's essay on my work] gives you jazz and science at the same time. I don't know whether to call his work "jazzy science" or "scientific jazz". Maybe it doesn't matter. In real life, after all, smart human beings follow more than one road from past to future (Tilly 2007: 13).
\end{abstract}

For Charles Tilly ${ }^{1}$ one of the most difficult and sophisticated task for social scientists is the search for causes and principles of variations. He was obsessed with the importance of causal explanation for social science and devoted all his intellectual energy to specify social mechanisms in order to get closer to explanation. In his epistemological perspective, social analysts have to identify mechanisms and processes (that is, recurrent configurations of specific social mechanisms) for explaining social phenomena. During all his life as a social analyst, he was preoccupied with tracing causal processes by identifying social mechanisms (transforming effects) that links causes and outcomes. From his early studies on migration and urbanization to his analyses on state formation, democratization and contention, all his sociological work underlines remarkably this epistemological concern. And, over the years, Tilly has elaborated a mechanism-and-process approach to causation (Tilly 2001).

Although this concern was under discussion since his first studies, the way to achieve causal explanation was not initially fixed. To find social mechanisms in order to get closer to explanation was, as he said himself,

\footnotetext{
1 I dedicated this essay to Chuck who influenced me and many of his students so deeply. I regret that I cannot discuss this essay with him and receive his cutting comments as he always did. I turn to Doug McAdam, one of his closer intellectual companions, to improve this essay. I am grateful to Doug and the editors of this volume for their stimulating comments on this paper.
} 
an "erratic itinerary" made of "sequences of trial, error, critique, correction, and reformulation" (1997: 12). During his intellectual itinerary, and without denying the importance of environmental mechanisms, he focused more intensively on the combination of relational and cognitive mechanisms to explain political processes. Although interactive mechanisms were already central in Tilly's work, social interactions combined with narratives (and shared understandings) became gradually more central in his theoretical framework. To concentrate on relational and cognitive mechanisms allowed him, first, to remain in his epistemological tracks by tracing mechanisms and processes at stake, and in fine to highlight causal explanation. Second, it offered Tilly a theoretical toolkit to emphasize both contingency and variation in social outcomes.

Relational realism progressively constituted a theoretical stand in Tilly's work. By analyzing the guerrilla force of Chiapas, he raised a set of old sociological questions on the link between discursive constructions and social processes, and our capacity to move from description to explanation by analysing discursive accounts. Tilly's response was straightforward.

After years of denial, I have come to think that failure to address these pressing questions directly $[\ldots]$ has cramped the credibility and fruitfulness of what could be a rich renewal of relational realism

He added:

[i]t is time to rediscover the centrality of social transactions, ties, and relations to social processes and to investigate connection between social relation on one side, and social construction, on the other. Structural realism stands as the thesis, social construction as the antithesis [...] and the relational realism as the hoped-for synthesis (2002: 5).

The interplay between social transactions and cognitive processes became central in his work. However, social interactions and narratives are not separate from institutional settings. Relational realism is a concrete way to connect structure and action, and this connection is ensured through dynamic processes.

The aim of this paper is to discuss Tilly's intellectual itinerary in which social transactions and narratives became more central in his theoretical framework. I discuss this itinerary by narrowing my empirical focus to Tilly's work on contention. As large-scale processes, first, I present a genealogy of Tilly's definition of social movements. Second, I examine his reformulation of contentious repertoire. Third, I discuss the importance of 
his theoretical thinking for a better understanding of small-scale processes such as people joining collective action. Finally, I conclude the paper with a few implications of Tilly's theoretical framework for social scientists.

\section{From Action to Interaction}

Before Tilly's pathbreaking book, From Mobilization to Revolution, the common view of social movement was a rather static understanding of protest politics centred on the analysis of organizations. Organizations constituted the basic unit of analysis of collective action. For Tilly protest politics is much more complex than groups: it involves interactions. Moreover, "collective action is about power and politics" (1978). He thus proposed a definition of collective action that takes into account power and politics in an interactive framework. He defined social movements as

\footnotetext{
a sustained series of interactions between powerholders and persons successfully claiming to speak on behalf of a constituency lacking formal representation, in the course of which those persons make publicly visible demands for changes in the distribution or exercise of power, and lack those demands with public demonstrations of support (1984: 306). ${ }^{2}$
}

The understanding of social movements changed radically with Tilly's works. He brought an interacting perspective in which social movements are thought of as political performances. In addition to bringing action into our conception of collective action, he allowed us to think of collective action in an interactive framework. Political performances are generated by a complex process, which is constructed through social interactions between powerholders and contenders on one side, and within contenders, on the other. A new world of research opened up. It opened a way to analyze forms (and variations among forms) of interactions between state and political challengers. It also opened up an avenue to study interactions among parties and to analyze identities people deploy in political claim-making. It pushed scholars to study identity construction (and identity transformation) in the course of multiple and complex social interactions.

The analysis of protest through social interactions changed radically our conception of political contention. It was a theoretical revolution as

\footnotetext{
2 Italics are mine.
} 
well as a methodological one. ${ }^{3}$ However, Tilly's conception of contentious politics was not fixed for ever. His intellectual itinerary led him to strengthen his understanding of social interactions. During the nineties, he conceived protest as "a complex form of social interactions" (1993-1994: 5) that he frequently compared to a jam session. In that perspective "[s]ocial movements cannot have self-reproducing natural histories because they consist of intermittent interactions among challengers, powerholders, audiences, and often many other parties" (p.6). ${ }^{4}$ To focus on social interactions implies to focus on shared knowledge, social scripts and narratives. Without common scripts and knowledge usually there is no interaction. As he said himself: "[s]ocial interactions vary in the extent to which they follow explicit models known to the parties" (1997: 1). Social interactions take place within relatively shared understandings, scripts and narratives that are transformed within the course of interactions. By combining social interactions with shared narratives Tilly was, first, able to specify social mechanisms and processes, and to get closer to explanation of contentious outcomes. Second, it allowed him to identify principles of variations. Political contentions are contingent outcomes emerging through specific social interactions (between and within parties), and thanks to social narratives, scripts and shared understandings available to the actors. The interplay between interactions and narratives open up large sets of improvisations parallel to jam sessions.

\section{Action Repertoire under Revision}

The search for original invention in the social movement as a specific form of claim-making was central in Tilly's studies of contentious politics $(1986,1995)$. He devoted intellectual efforts to understand invention but also transformation of social movement repertoire. In The Contentious French, he pointed out a shift of protest action repertoire from parochial, particularistic, and patronized forms of claim-making to autonomous, national, and modular forms of action. Transformations of action repertoires were explained by a profound alteration in social structures. One of the

\footnotetext{
3 The understanding of social movements as political performances (sustained interactions and claim-makings) brought new methodological tools to analyze protest politics: the "event protest analysis" (see Rucht et al. 1998).

4 Italics are mine.
} 
major alterations was the emergence of national politics. Tilly's early understanding of action repertoire identifies one major interactive process, which is between state and challengers. Action repertoire was understood as a set of "limited number of known sequences of acting together" available to the contenders and "those established forms change as a result of collective learning and of changes in supporting social structure" (1997: 11 ; 1984). As he underlined, both collective learning and social structure change usually in a concomitant process. They change as a bloc that affects forms of popular collective action. In this early conception, shifts in action repertoires were explained by a limited view of social interactions. A rather structural account combined with an instrumental adaptation of contenders to social structure changes explain shift in action repertoire.

Among several problems of his conception of action repertoire, one was particularly unacceptable for Tilly who was so obsessed by causal explanation: "it offered no coherent causal account for changes in repertoires" (1997: 11). A deeper conception of social interactions in combination with social narratives and shared understandings was the way followed by Tilly to avoid this pitfall. Relational realism was the solution to the problem and a new understanding of action repertoire emerged.

\footnotetext{
Repertoires rested on extensive shared understandings concerning possible forms of action and their links to possible outcome, [...] they consisted of well-defined improvisatory performances within broadly defined scripts, $[. .$.$] each performance$ linked at least two parties of mutual claim makers, and [...] changes in performances occurred as a consequence of strategic interactions between and among the parties, both within and outside open moments of contention (1997: 11).
}

The revised conception gave a larger place to intermittent interactions (between and within parties) and also a larger place to shared understandings and social narratives than in his previous works. This new formulation was adopted in Popular Contention in Great Britain.

\section{Tilly's Theoretical Perspective for Small-scale Processes}

What can we learn from Tilly's itinerary to explain people commitment to collective action? Tilly was interested in large-scale social processes. However, one of his last books, Why?, deals with small-scale processes. He studied the reasons given by people to justify what they do or to explain what takes place in their environment. Relational realism was also adopted 
in his understanding of reason giving. Here again, social interactions, narratives and people practices are closely connected to one another.

As many social movement scholars underline, social interactions play a key role for joining collective action (e.g. Snow et al. 1986; McAdam 1988; Klandermans 1993; Gould 1995). In line with White's conception of social networks as "islands of meanings" (1992: 67), scholars stress that social interactions shape people's cognitive map continuously which in turn facilitate (or not) their commitment to contentious politics (e.g., Passy 1998, 2002). This conception allows making sense of variations. With Tilly's theoretical framework we can go a step further. Borrowing the conception of mental models from Bower and Morrow (1990), Tilly defined "Mental models as narratives" (1997: 21). He added: "[a] mental model ordinarily takes the form of play with actors who cause new events and changes appear as the text unfolds". This conception brings new principles of variation in the understanding of how and why people join protest politics. His theoretical perspective invites us to take both social interactions and narratives as key social mechanisms to understand people activism. Social interactions certainly refine variation for joining political protest, but narratives too. Here again, we are much closer to a jam session than to a determinist path leading individuals to collective action.

\section{A Few Implications for Social Scientists}

Tilly's itinerary, moving from interactions to relational realism, led him to strengthen his conception of social relations but also to bring together in a coherent theoretical framework social relations and narratives. Investigating the interplay between social transactions and cognitive mechanisms led him to get closer to causation and to underline variations at stake. His theoretical thinking has many implications for social movements scholars as well as for social scientists. Due to space constraints, I will describe here only one theoretical implication and one methodological one.

Tilly's conceptual framework takes us away from social determinism as well as social action free of any constraints. Shared knowledge, scripts, and narratives are essential for social interactions to take place but those interactions take different forms (Tilly 1997). When actors (collective or individual) relate on extensive social scripts and abundant shared knowledge they rely on strong routines for their interactions. By contrast, when scripts are thin and the knowledge shared among actors is low their interac- 
tions parallel improvisations. And between these two extremes, a vast continuum of social interactions takes place. Routine social interactions favour a sort of "reproduction" (usually made of imperfections) of known actions while improvisation favour more agency and variations among actions. This implies that social outcomes are contingent and made of important source of improvisation cause, first, by the multiple combinations existing between social interactions and shared understandings, and, second, by the incessant trial, error, and error corrections of social action (Tilly 1996). As Tilly declared: "any complex social structure that accomplished the miracle of complete scripting and exact conformity would quickly freeze and crack" (1997: 6). Pure reproduction of social actions is thus impossible or is akin to a miracle.

However, Tilly's theoretical thinking does not imply that "social life lacks of order" (1997: 6). Social life is not founded on deep disorder. "Social interactions wreaks it effects through script-adopting improvisation within limits set by existing social networks and shared understandings" (1997: 6). The frame within which social interactions take place is bounded by shared knowledge, existing scripts and narratives, and by networks at stake. Agency, creativity, and imprecision are thus under constraints. In addition, previous interactions limit what can happen in the next set of social relations. Social activity is thus path-dependent. For example, chains of interactions in contentious politics constrain next interactions. With Tilly's theoretical thinking we are far away from social activity released from constraints.

Social outcomes are not emerging from pure chaos, but from a relative chaotic interplay within limits set by existing shared understandings, common scripts and narratives, and by existing social networks. This theoretical thinking has an obvious methodological implication. Social analysts have to follow social outcomes made of improvisations within constraints fixed by social ties and shared understandings. Large-scale processes, such as contentious politics, should be analyzed by asking how historical accumulations of experiences provide shared understandings that constraint and guide next chains of interactions. Social scientists should focus their study on shared knowledge, common scripts and narratives, as well as on a set of social relations at stake in order to make sense of social outcomes. In addition, they have to take chains of interactions within a time-perspective. For example, Tilly advised social movement scholars to "describe interaction over collective claims as they measure the magnitudes of claim making, interactions, and outcomes". He added "they must also explain the 
loop from social organization to claims to interactions to outcomes, then back to new social organization and new claims" (2008: 31$)$. Methodologically a key element is to sequence social processes to get closer to chains of interactions and to map shared understandings. For small-processes, such as processes letting people to join contentious politics, social scientists should have similar concerns. Here again, we have to penetrate into sequences of action (Stinchcombe 2005). This implication, underlined here specifically for social movements scholars studying large-scale or smallscale processes, are transposable for social scientists analyzing any other social and political outcomes.

The agenda for social analysts set by Tilly is rather ambitious. Moreover, it is not easy to implement. The main difficulties at stake are methodological. For example, to trace chains of interactions are far from easy. ${ }^{5}$ However one thing is clear, Charles Tilly's legacy is considerable. His intellectual itinerary (made of deep interactions and of revised scripts) allowed him to elaborate over the years a theoretical toolkit and an epistemology that opens up new roads for social research. He blew a revolutionary wind on social movement studies, and this wind goes largely beyond this field of research.

\section{References}

Bower, Gordon H. and D. Morrow (1990). Mental Models in Narrative Comprehension. Science 247: 44-8.

Gould, R. (1995). Insurgent Identities. Class, Community, and Protest in Paris from 1848 to the Commune. Chicago: Chicago University Press.

Klandermans, B. (1997). The Social Psychology of Protest. Oxford: Blackwell.

McAdam, D. (1988). Freedom Summer. Oxford: Oxford University Press.

McAdam, D., Tarrow, S. and C. Tilly (2008). Methods for Measuring Mechanisms of Contentious. Qualitative Sociology 31: 307-31.

Passy, F. (1998). L'action altruiste. Contraintes et opportunités de l'engagement individuel dans les mouvements sociaux. Genève: Droz.

\footnotetext{
5 Tilly and his research companions, Doug McAdam and Sidney Tarrow, underline few ways to achieve this goal (McAdam et al. 2008).
} 
- (2003). Social Networks Matter. But How? In Diani, M. and D. McAdam (eds.), Social Movements and Networks. Relational Approaches to Collective Action. Oxford: Oxford University Press.

Rucht, D., Koopmans, R. and F. Neidhart (eds.), (1998). Act of Dissent. New Development in the Study of Protest. Berlin: Edition Sigma.

Stinchcombe, A. (2005). The Logic of Social Research. Chicago: Chicago University Press.

Tilly C. (1978). From Mobilization to Revolution. Prentice-Hall: Englewood Cliffs.

(1984) Social Movements and National Politics. In Bright, C. and S. Harding (eds.), Statemaking and Social Movements. Ann Arbor: University of Michigan Press.

(1986). The Contentious French. Cambridge: Harvard University Press.

(1993-1994). Social Movements as Historically Specific Clusters of Political Performances. Berkeley Journal of Sociology 38: 1-30.

(1995). Popular Contention in Great Britain, 1758-1834. Cambridge: Harvard University Press.

(1996). Invisible Elbow. Sociological Forum 4: 589-601.

(1997). Roads from Past to Future. Laham: Rowman and Littlefield.

(2001). Mechanisms in Political Processes. Annual Review of Political Science 4: 21-41.

- (2002). Stories, Identities, and Political Change. Lanham: Rowman and Littlefield.

- (2006). Why. Princeton: Princeton University Press.

White, H. (1992). Identity and Control. Princeton: Princeton University Press.

Contact: Florence.Passy@unil.ch (Florence Passy). 